\title{
Printed Nanostructures for Organic Photovoltaic Cells and Solution-Processed Polymer Light-Emitting Diodes
}

\author{
Hongseok Youn, ${ }^{[\mathrm{a}]}$ Hui Joon Park, ${ }^{*[\mathrm{~b}]}$ and L. Jay Guo ${ }^{*[\mathrm{c}]}$
}

We review the progress on printing-based technologies for organic electronic devices, especially organic photovoltaic (OPV) cells and polymer light-emitting diodes (PLEDs). First we discuss recent efforts to introduce interdigitated nanostructures on the order of tens of nanometers to the photoactive layers of OPV cells using nanoimprint lithogra- phy including a soft-printing process developed in our research group that can easily produce sub- $20 \mathrm{~nm}$ scale organic semiconductor nanopillars. Second, we review solution-processible printing technologies such as gravure printing, screen printing, blade coating, and slot-die coating for highthroughput manufacturing of PLEDs.

\section{Introduction}

Polymer electronic devices such as organic photovoltaic (OPV) cells and polymer light-emitting diodes (PLEDs) have great potentials toward scalable, flexible, light-weight, and low-cost devices. Moreover, the polymer electronic devices can be produced by using broad range of low-cost manufacturing technologies such as the roll-to-roll, inkjet, blade, and spray coating methods. In particular, recently, the power conversion efficiency (PCE) of the OPVs employing a lowband-gap polymer exceeds approximately $10 \%$, which has caught the attention of researchers. ${ }^{[1-4]}$

However, polymer electronic devices are still facing manufacturing and efficiency issues in scalable devices. To realize future power sources and next-generation solid-state lighting, significant effort is required to address important challenges. In this Review, we will focus the recent efforts that have utilized printing-based nanoimprint lithography (NIL) to fabricate ideal interdigitated heterojunctions for efficient OPV cells. Next we will move to solution-processed PLEDs and then introduce various printing and coating technologies for solution-processed PLEDs dealing with the coating/printing issues that are important for fabrication.

\section{Nanoimprint Lithography for Organic Photo- voltaics}

OPVs have been highlighted for next-generation PV technologies due to such advantages as low cost, ease of fabrication, and flexibility. However, the low PCE values of OPV cells (compared to inorganic materials-based PV cells) should be solved for the practical application of this technology. Because most organic semiconductors have low dielectric constants, photo-generated positive and negative charge pairs (i.e., excitons) are strongly bound, consequently having inherently short exciton diffusion lengths, known to be approximately $10 \mathrm{~nm} \cdot{ }^{[5-13]}$ Therefore, bulk heterojunctions (BHJs), composed of interpenetrating nanoscale networks of electron-donor (donor) and electron-acceptor (acceptor) materi- als within tens of nanometers distance have been extensively investigated, as photogenerated excitons can be efficiently dissociated at the donor/acceptor interface. ${ }^{[14-24]}$ However, the donor and acceptor nanodomains, randomly distributed in the BHJ structure, inevitably have inferior charge transport properties, so improving the organization of nanodomains has been one of the major issues to be resolved in this structure.

More importantly, interdigitated donor-acceptor nanostructures at a scale of tens of nanometers (comparable to exciton diffusion distance of organic semiconductor) have been commonly known as ideal structures for organic heterojunctions, advantageous to efficient exciton dissociation with superior charge transport. ${ }^{[25,26]}$

To demonstrate those nanostructures, various approaches have been developed until now that supported the effectiveness of the bulk heterojunction approach to OPVs. Among them, printing-based technologies are quite important for processing, among which NIL is one of the successful lithographic techniques capable of replicating large-area nanostructures in the photoactive layer of OPV cells with resolu-

\footnotetext{
[a] Dr. H. Youn

Department of Mechanical Engineering

Hanbat National University

125 Dongseodaero

Yuseong-gu Daejeon, 305-719 (Korea)

[b] Prof. H. J. Park

Division of Energy Systems Research Ajou University

Suwon 443-749 (Korea)

E-mail: huijoon@ajou.ac.kr

[c] Prof. L.J. Guo

Department of Electrical Engineering and Computer Science

University of Michigan

Ann Arbor, MI 48109 (USA)

E-mail: guo@umich.edu

(1) Part of a Special Issue on "Printed Energy Technologies". To view the complete issue, visit:

http://onlinelibrary.wiley.com/doi/10.1002/ente.v3.4/issuetoc
} 
tion down to tens of nanometers. ${ }^{[27]}$ This section summarizes the efforts that have utilized printing-based NIL technologies to realize interdigitated heterojuncitons for efficient OPV cells, including recent progresses developed in our research group that can access sub-20 nm scale organic semiconductor nanostructures within short processing time (tens of seconds).

In addition to the NIL-based top-down approaches focused on in this section, various bottom-up approaches to

\begin{abstract}
Hongseok Youn received a B.S. degree in mechanical engineering at Korea University, Korea in 2001. He received M.S. and Ph.D. degrees in mechanical engineering at Korea Advanced Institute of Science and Technology in 2005 and 2011, respectively. From 2011 to 2014, he was a postdoctoral researcher in electrical engineering and computer science at the University of Michigan, Ann Arbor, USA. After completing postdoctoral research, he joined as a senior researcher at the National Center for Nanoprocessing and Equipment at the Korea Institute of Industrial Technology (KITECH).

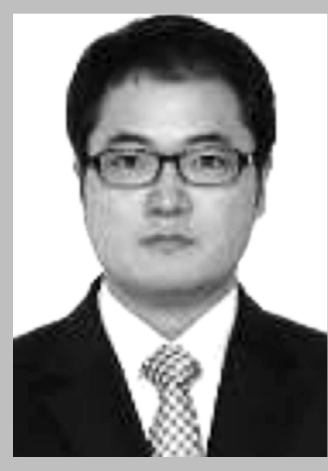

Hui Joon Park received B.S. and M.S. degrees in materials science and engineering from Seoul National University, Korea, in 2002 and 2004, respectively. From 2004 to 2006, he was with LG Electronics as a Research Engineer. From 2006 to 2007, he was a Research Scientist at the Korea Institute of Science and Technology, Korea. He received a Ph.D. degree in organic electronics and nanofabrication at the University of Michigan, Ann Arbor, USA, in 2012. After completing his

Ph.D., he was a Senior Research Engineer at Intel Corporation, USA, from 2012 to 2014. Since 2014, he has been in the Division of Energy Systems Research, Ajou University, Korea, where he is currently an Assistant Professor.

L. Jay Guo started his academic career at the University of Michigan in 1999 and is currently Professor of Electrical Engineering and Computer Science, with joint appointments in Mechanical Engineering, Macomolecular Science and Engineering, and Applied Physics. He has 160 refereed journal publications. His group's research includes polymer-based photonic devices and sensor applications, organic and hybrid photovoltaics, plasmonic nanophotonics/metamaterials, as well as nanoimprint-based and roll-to-roll nanomanufacturing technologies. grow nanostructures on the substrate have also been extensively investigated. For instance, donor materials that can spontaneously form vertically oriented nanocolumn structures during crystallization have been developed, ${ }^{[28]}$ and various types of nanopillar arrays were grown by thermal gradient sublimation, ${ }^{[29]}$ organic vapor-phase deposition (OVPD $),{ }^{[30]}$ or glancing angle deposition, ${ }^{[31,32]}$ as shown in Figure 1. However, the difficulties in precisely controlling the nanodomains of self-organized molecules, limited applicability to large-area manufacturing, and the long processing times of vacuum deposition remain to be addressed to make these approaches universal.

In contrast to bottom-up approaches, NIL-based top-down approaches have advantages such as easy control of nanodomains, large area applicability with short processing times, and high resolution. Kim et al. introduced interdigitated nanostructures between the donor and acceptor layers. They used NIL, to imprint a nanograting structure in the polythiophene derivative donor layer. The thermal treatment during NIL can render the material insoluble to organic solvents for the subsequent solution-casting of the acceptor material. Their imprinted PV cells showed 3-fold improved PCE values compared to the bilayer device; however, the inferior electrical properties of their polythiophene derivative, designed for the consecutive solution process, imposed a limitation to the overall performances, consequently yielding only $0.80 \%$ PCE in the nanostructured PV cell (Figure 2). ${ }^{[33]}$

Meanwhile, Aryal et al. reported an imprinted nanopillar structure of poly(3-hexylthiophene-2,5-diyl) (P3HT), of which the diameter was $80 \mathrm{~nm}$. They utilized nanoporous silicone as a NIL stamp, prepared by plasma etching using anodic alumina (AAO) membranes as an etch mask and then spin cast the PCBM acceptor onto the P3HT nanopillar structure using a semi-orthogonal solvent (e.g., dichloromethane) to complete the OPV structure. ${ }^{[34]}$ Chen et al. also demonstrated a P3HT nanopillar structure with $30 \mathrm{~nm}$ diameter. In this case, they directly utilized the AAO membrane as a NIL stamp after modifying the surface of the membrane by PDMS for better releasing and they also applied the orthogonal solvent approach for the subsequent acceptor layer (Figure 3) ${ }^{[35]}$ However, concerns about the perfect orthogonality of the solvent to donor and acceptor material that may be able to aggravate the underlying nanostructures during second layer formation remains as an issue of these approaches. $^{[36]}$

Alternatively oblique thermal deposition of $\mathrm{C}_{60}$ on the imprinted nanostructures, which is intended to form more uniform acceptor layer, has been suggested, but the different energy levels of $\mathrm{C}_{60}$ and PCBM inevitably induce a lower $V_{\text {oc }}$, which decreases the overall PCE. ${ }^{[37]}$ This trend was also shown in the work by Kim et al., which formed a $\mathrm{C}_{60}$ layer on $50 \mathrm{~nm}$ scale P3HT nanopillars. ${ }^{[38]}$ In their work, pillar structures were fabricated by infiltrating P3HT polymer into nanopores of an AAO membrane by using capillary action, and the AAO template was subsequently removed by using a selective solvent. Even though the PCE of the nanostructured device was improved by 6-fold compared to the planar 
(a)

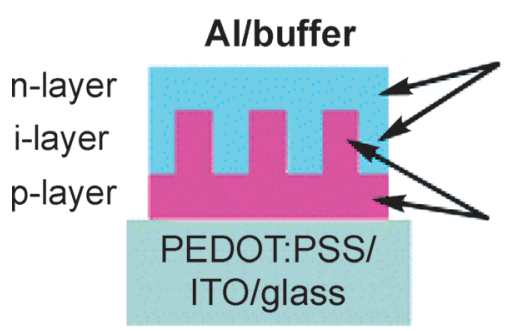

(b)

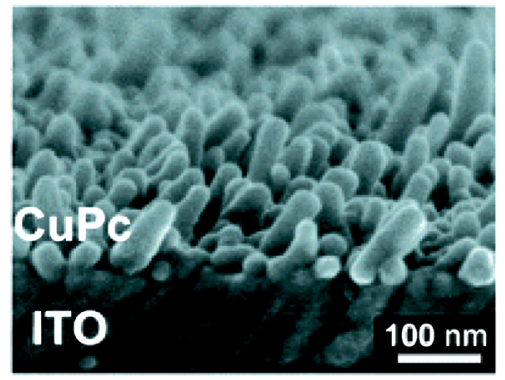

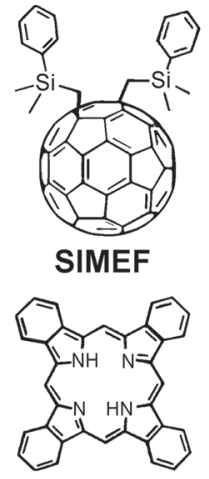

BP

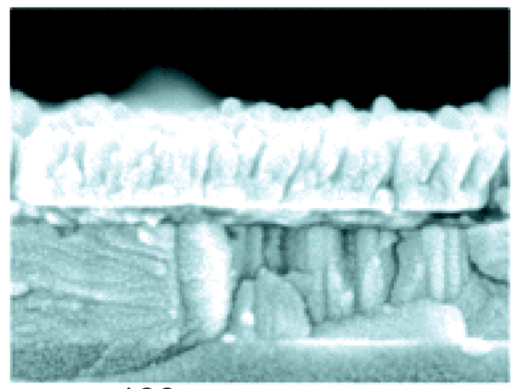

$100 \mathrm{~nm}$

columnar structure in the i-layer

\section{(c)}

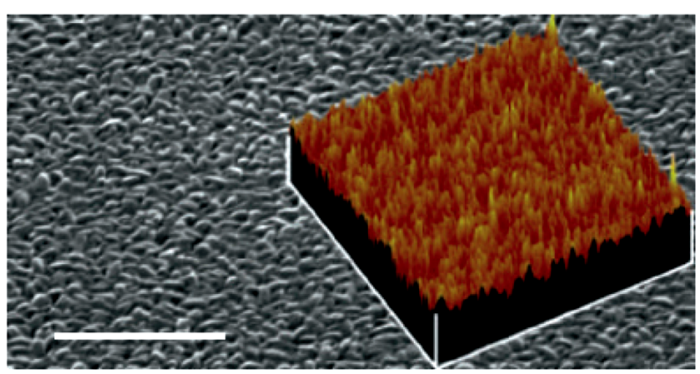

(d)
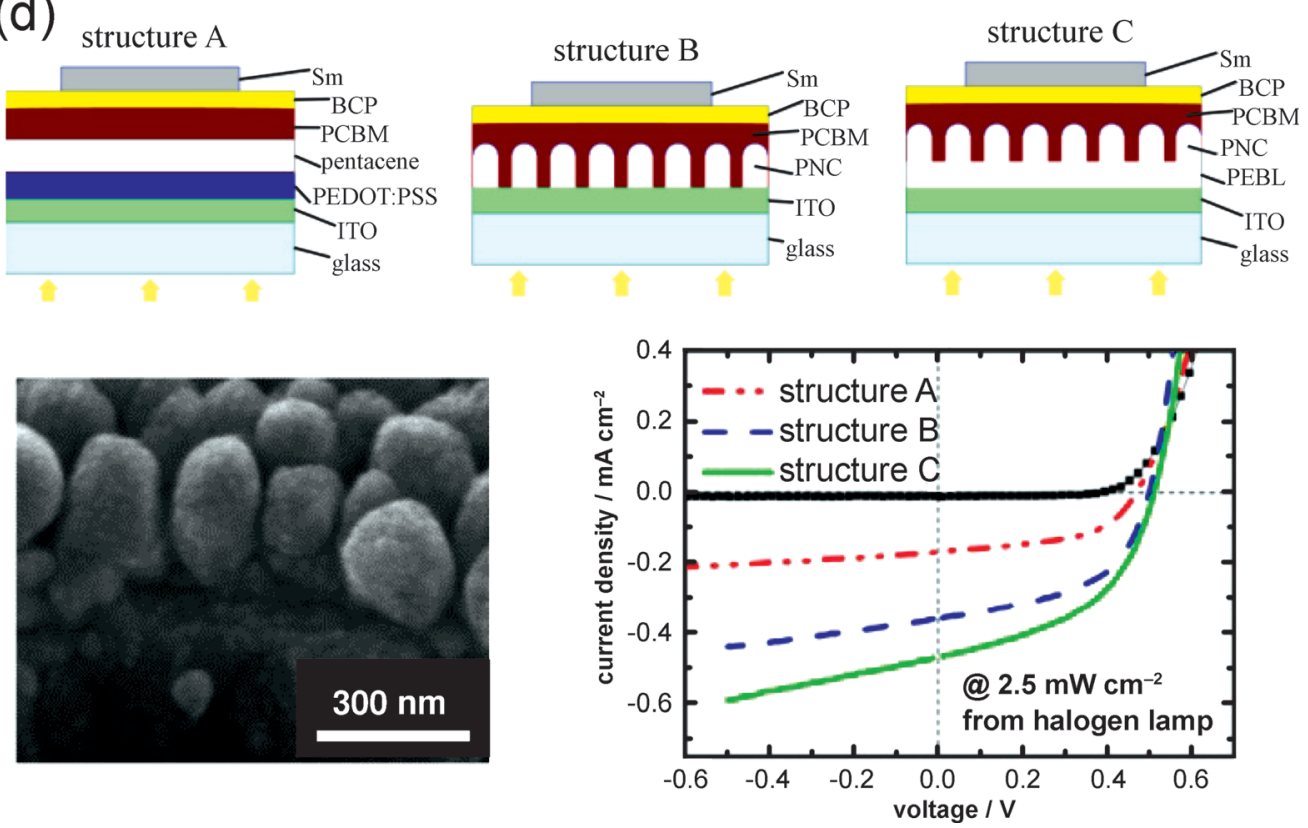

Figure 1. (a) OPV utilizing donor materials that can spontaneously form vertically oriented nanocolumn structures during crystallization, Reproduced with permission. ${ }^{[28]}$ Copyright 2009, American Chemical Society. (b) CuPc nanostructure grown by thermal gradient sublimation, Reproduced with permission. ${ }^{[29]}$ Copyright 2011, American Chemical Society. (c) CuPc nanostructure grown by OVPD, Reproduced with permission. ${ }^{[30]}$ Copyright 2005 , Macmillan Publishers Ltd. (d) Pentacene nanostructure grown by glancing angle deposition (GLAD) and device performances of OPVs. Reproduced with permission. ${ }^{[32]}$ Copyright 2011, Elsevier.

layout device, both PV cells inherently have lower $V_{\text {oc }}$ values $(\approx 0.5 \mathrm{~V})$ than those based on the PCBM acceptor $(\approx 0.6 \mathrm{~V})$ (Figure 4).

He et al. suggested a modified NIL-based process (termed the double NIL process), which utilizes a nanoimprinted or- ganic layer to imprint another organic film under solvent vapor conditions. ${ }^{[39,40]}$ In their works, OPV cells composed of P3HT and PCBM; poly[(9,9-dioctyluorene)-2,7-diyl-alt-(4,7bis(3-hexylthien-5-yl)-2,1,3-benzothiadiazole)-2',2"-diyl] (F8TBT) and PCBM; or P3HT and F8TBT as donor and ac- 


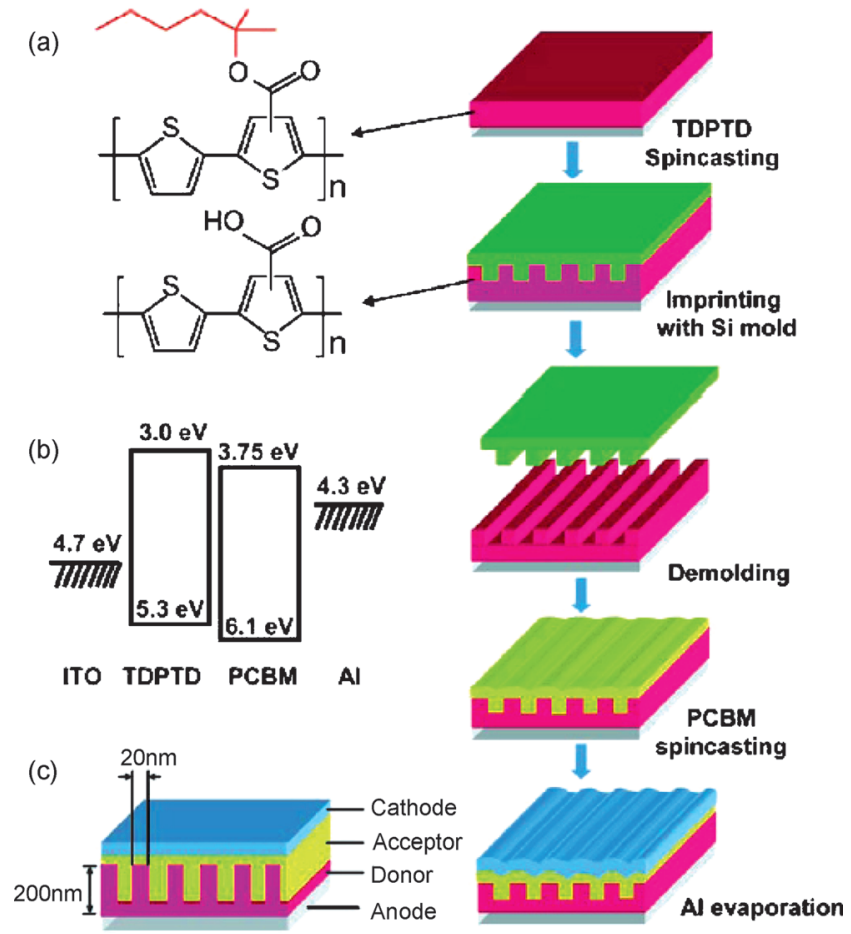

Figure 2. (a) Schematic of a nanoimprinted polymer PV cell, along with the materials and fabrication procedure used to achieve it. Here, on ITO-coated PET, a thermally deprotectable polythiophene derivative (TDPTD) was spin cast and then imprinted with a prepatterned stamp. During this imprinting process, the side group of TDPTD was deprotected by applying heat and the TDPTD became insoluble. PCBM was then spin cast and finally Al was evaporated to form the cathode layer. (b) Band structure of the fabricated cell. (c) An idealized diagram of an organic photovoltaic cell structure having an interdigitated donor-acceptor interface. Reproduced with permission. ${ }^{[33]}$ Copyright 2007, American Institute of Physics.
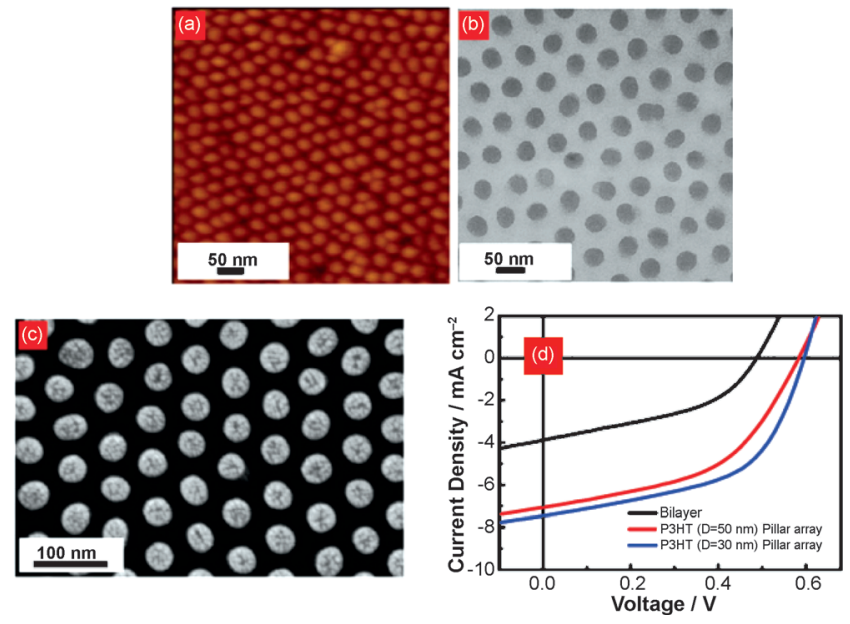

Figure 3. Micrographs of free-standing P3HT nanopillars: a) SFM of the freestanding $\mathrm{P} 3 \mathrm{HT}$ pillars $(D=30 \mathrm{~nm})$; b) TEM of the free-standing $\mathrm{P} 3 \mathrm{HT}$ pillars; c) SEM of the freestanding P3HT pillars. d) $J-V$ curve of the devices based on different textures. Reproduced with permission. ${ }^{[35]}$ Copyright 2012, American Chemical Society.

ceptor pairs, were prepared; they showed that the performances of the OPV cells were systematically improved as the interfacial area increased. This effect originates from the smaller dimensions of the nanostructure, which reached as low as $25 \mathrm{~nm}$ scale (Figure 5).

Imprinted P3HT nanostructures can even reach the $15 \mathrm{~nm}$ scale as demonstrated by our research group. Sub-20 nm scale block-copolymer self-assembled nanostructures could be transferred to a $\mathrm{SiO}_{2}$ layer in large-area format, which can then be utilized as NIL stamp; the fabrication of approximately $15 \mathrm{~nm}$ scale pillar- and hole-type nanostructures in the P3HT layer is possible using those $\mathrm{SiO}_{2}$ stamps of both polarity patterns (Figure 6). ${ }^{[4]}$

This process could be further extended to solution-based soft-printing lithography, and high-aspect-ratio polymer semiconductor nanopillars having $15 \mathrm{~nm}$ diameter were successfully demonstrated by utilizing PDMS nanohole-type soft stamps (Figure 7a) prepared by using the $\mathrm{SiO}_{2}$ nanopillar structure (Figure 6b). Figure 7b-d shows nanopillar structures of widely utilized polymer semiconductors such as P3HT, poly[N-9' -hepta- decanyl-2,7-carbazole-alt-5,5-(4',7'di-2-thienyl-2', $1^{\prime}, 3^{\prime}$-benzothiadiazole)] (PCDTBT), and poly(indacenodithiophene-co-phenanthro[9,10-b]quinoxaline) (PIDT PhanQ). This process is also applicable to solutionprocessible, small molecular organic semiconductors. As shown in Figure 7e,f, $15 \mathrm{~nm}$ scale high-aspect-ratio nanopillars of 2,4-bis[4-( $N$-phenyl-1-naphthylamino)-2,6-dihydroxyphenyl] squaraine (1-NPSQ) (utilized as donor) were realized with a fullerene derivative used as the acceptor. The processing time for this solution-based printing process can be reduced to a few seconds, which is promising for high-speed roll-to-roll process.

Even though interdigitated heterojunction structures have shown positive effects on the performance of OPV cells compared to the control devices (planar-structured PV cells in most cases), innovative device architectures and processes are still needed to realize interdigitated heterojunction OPV cells that can overwhelm BHJ-based PV cells, as most of people have expected; the nanostructures should be precisely controlled using high-performance donor-acceptor systems without destroying those nanostructures or degrading electrical properties of the materials.

\section{Solution-Processed Polymer Light-Emitting Diodes}

PLEDs have fascinating potential for low-cost, scalable nextgeneration displays and solid-state lighting. As polymers can be dissolved in organic solvents, PLEDs can be made by utilizing high-throughput manufacturing technologies such as roll-to-roll printing and screen printing. However, PLEDs still utilize oxygen- and moisture-sensitive materials such as electron-transport and electron-injection layers in the device structure. Conventional electron injection materials such as $\mathrm{Li}, \mathrm{Ca}, \mathrm{Ba}$, and $\mathrm{Cs}$ metals are very effective at injecting electrons into the light-emitting polymer layer, but these alkali or alkaline earth metals can react with oxygen in the air. In particular, more recently, $\mathrm{LiF}, \mathrm{CeF}, \mathrm{NaF}, \mathrm{Cs}_{2} \mathrm{CO}_{3}$ have been widely used with an aluminum cathode. ${ }^{[42-47]}$ However, these materials are still sensitive to the oxygen and moisture in the 
(a)
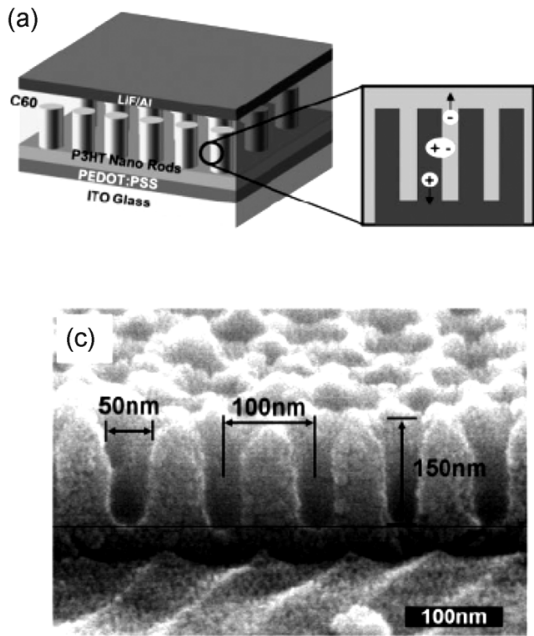

(e)

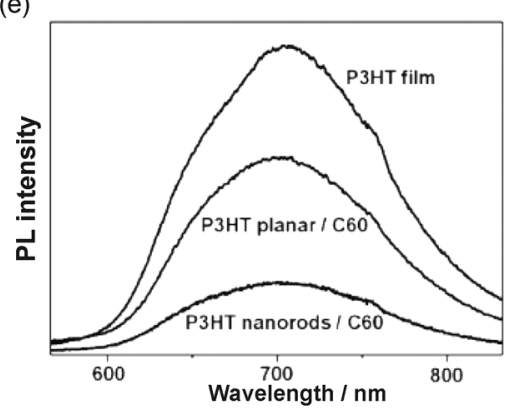

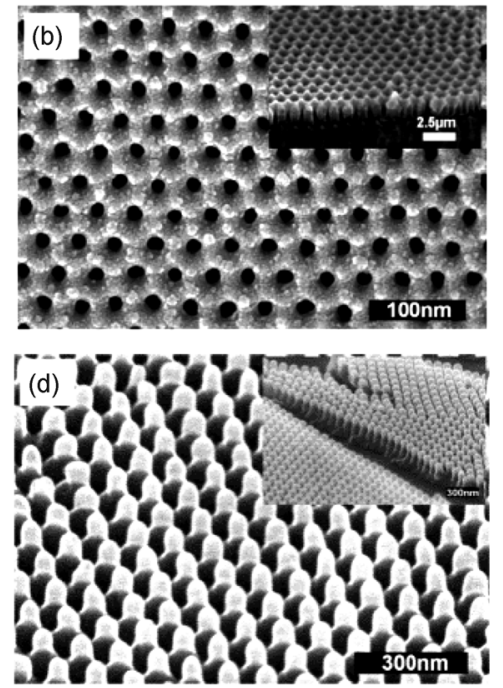

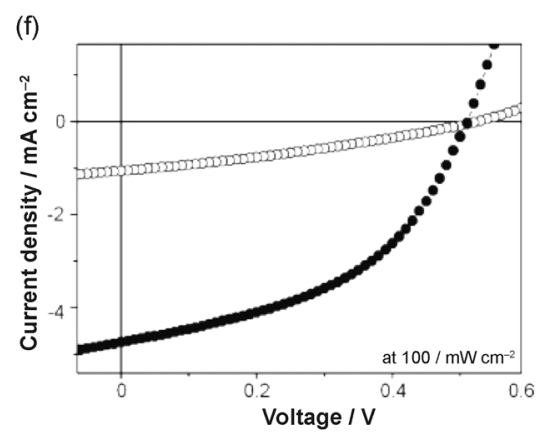

Figure 4. a) Schematic representation of the P3HT nanorod/ $C_{60}$ structured solar cell architecture and photoinduced charge separation at the interface between the donor and acceptor. (b,c) FE-SEM images of the AAO template: top and side views, respectively, of the template with pore diameters of $50 \mathrm{~nm}$, interpore size of $100 \mathrm{~nm}$, and depth of $150 \mathrm{~nm}$. d) FE-SEM images of $\mathrm{P} 3 \mathrm{HT}$ nanorods made using the $\mathrm{AAO}$ template, after removal of the $\mathrm{Al} / \mathrm{Al}_{2} \mathrm{O}_{3}$ layer. (d) Photoluminescence spectra of a P3HT single-layer film and solar cells constructed using planar $\mathrm{P} 3 \mathrm{HT} / \mathrm{C} 60$ and $\mathrm{P} 3 \mathrm{HT}$ nanorods $/ \mathrm{C}_{60}$. e) Current density-voltage $(\mathrm{J}-\mathrm{V}$ ) curves of photovoltaic devices under white light (the AM 1.5 conditions): planar $\mathrm{P} 3 \mathrm{HT}$ film/ $\mathrm{C}_{60}$ solar cell $(\mathrm{O})$, $\mathrm{P} 3 \mathrm{HT}$ nanorod/C60 solar cell $(\mathbf{O})$. Reproduced with permission. ${ }^{[38]}$ Copyright 2010, Wiley.

air condition and toxic to the human body. ${ }^{[43]}$ Thus, these reactive materials are usually deposited in a high vacuum chamber. Moreover, the alkali-halide electron injection materials need to be ultra-thin (less than $2 \mathrm{~nm}$ ) for good electron injection. The electron-injection behavior depends on the morphologies of the underlying layers due to its ultrathin size. This is the reason why previous reports on printed and solution-processed PLEDs are limited to only two layers (i.e. the hole injection layer and emissive layer) ${ }^{[48]}$ This section introduces various printing and coating technologies for solution-processed PLEDs and deals with coating/printing issues for fabricating PLEDs.

\subsection{Solution-processible electron-transport/injection materials}

In most printed PLEDs, poly(3,4-ethylenedioxythiophene): polystyrene sulfonate (PEDOT:PSS) and emissive materials are fabricated by using printing technologies. However, the electron transport/injection layers are relatively thin and unstable in air. Recently, many researchers have focused on de- veloping new materials that can be processed by practical fabrication methods. Among the solution processible materials, organic surfactant-like materials, such as polyethylene oxide (PEO) and polyethylene glycol (PEG) have good electron-injection characteristics. In addition, PEO and an ammonium ion complex were reported to enhance the current efficiency because the ionic separation and formation of dipole layer significantly lower the electroninjection barrier (Figure 8).

Moreover, water-soluble conjugate polymers possessing ammonium ions or amino groups are frequently employed as the electron-injection layers. For example, water/alcohol-soluble or surfactant-like polymers of poly[ $(9,9-$ bis $(30-(N, N$-dimethylamino)propyl)-2,7-fluorene)alt-2,7-(9,9-dioctylfluorene)] (PFNR $\left.{ }_{2}\right), \quad$ poly $\{[9,9-$ bis $(6 '-$ (N,N,N-trimethylammonium)hexyl)fluorine-2,7-diyl]-alt[2,5bis(pphenylene)-1,3,4-oxadiazole]\} ( $\left.\mathrm{PFON}+\left(\mathrm{CH}_{3}\right) 3 \mathrm{I}-\mathrm{PBD}\right)$, poly[9,9-bis(6'-(diethanolamino)hexyl) fluorene] (PFN-OH), and poly[ $(9,9-$ bis $((60-(N, N, N-$ trimethylammonium)hexyl)2,7-fluorene)-alt-(9,9-bis(2-(2-

(2-methoxyethoxy)ethoxy)eth-

yl)-9-fluorene)) (WPF-6-oxy-F) are representative solutionprocessible electron-injection materials. More recently, water-soluble polymers such as poly [(9,9-bis(3- $(N, N$-dimethylamino)propyl)-2,7-fluorene)-alt-2,7-(9,9-dioctylfluorene)] (PFN) and polyethylenimine ethoxylated (PEIE) have been developed with many amino groups. These amino groups can effectively create interface dipoles at various metal surfaces, which can reduce the work functions of the metals as shown in Figure 9. The water-soluble polymer, PFN has better current efficiency than a $\mathrm{Ba}$ electrode, as illustrated in Figure 10.

\subsection{Printing/coating technologies for solution-processed PLEDs}

This section will introduce the general printing/coating processes for PLEDs such as gravure printing, screen printing, blade coating and slot-die coating. The traditional inks and solutions in printing/coating processes are fully optimized for fast mass production. However, some materials in organic electronic devices are not appropriate for the conventional 

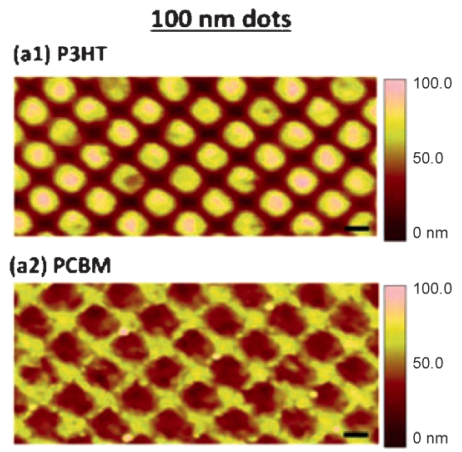

Imprinted P3HT:PCBM film

(a)
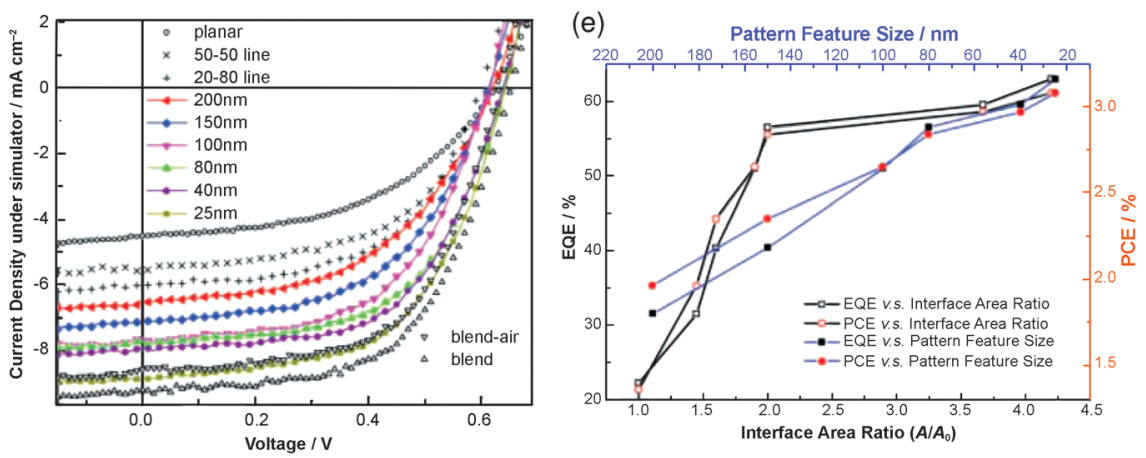

Figure 5. AFM (a1-b2) and SEM (c1, c2) images of double imprinted films. Plan-view AFM images of the P3HTPCBM pair (a1-a2) pair showing a grid of $100 \mathrm{~nm}$ wide dots. Similar 3D AFM images of an imprinted grid of $80 \mathrm{~nm}$ wide dots (b1, b2); SEM images of the PCBM-F8TBT (c1-c2) pair showing a square lattice of $25 \mathrm{~nm}$ diameter dots and holes. (d) $J-V$ characteristics of the double-imprinted P3HT:PCBM PV cells for a series of feature sizes in comparison to planar and blend control cells under solar illumination conditions. (e) EQE and PCE. Reproduced with permission. ${ }^{[40]}$ Copyright 2011 , Wiley.
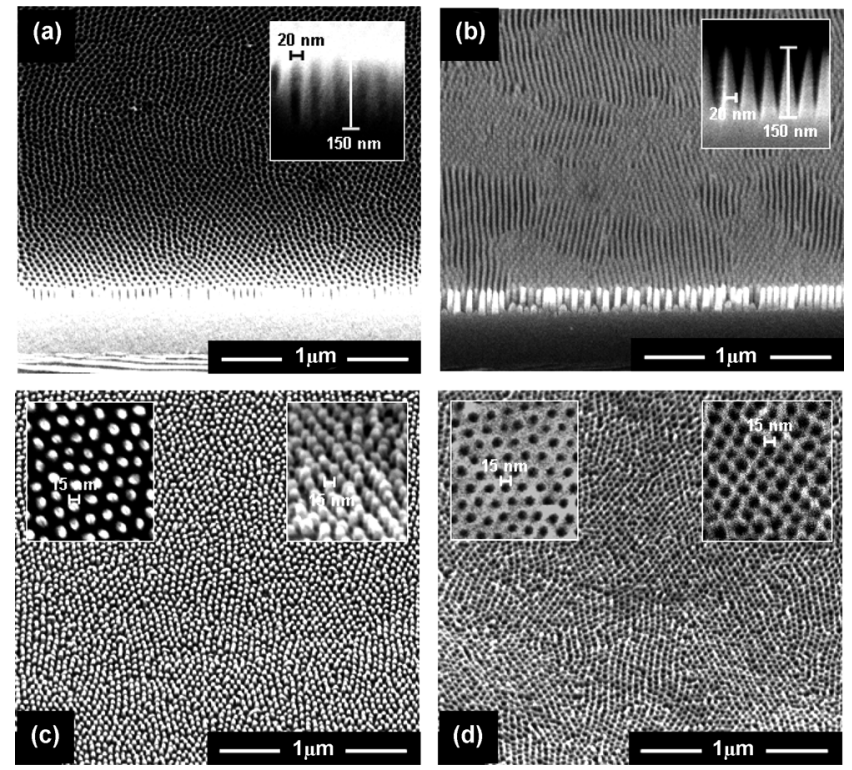

Figure 6. (a) $\mathrm{SiO}_{2}$ nanohole structure. (b) $\mathrm{SiO}_{2}$ nanopillar structure. (c) Imprinted P3HT nanopillars. (d) Imprinted P3HT nanoholes. Reproduced with permission. ${ }^{[41]}$ Copyright 2009, American Chemical Society.

printing process. Thus we need to carefully select the proper fabrication techniques for various functional materials. In

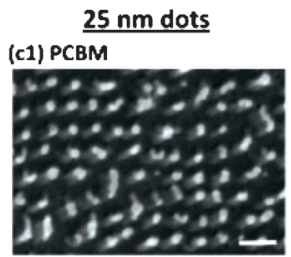

\section{(c2) F8TBT}

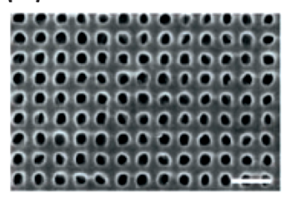

particular, the film thicknesses of the functional layers in PLEDs are very important and the layer thicknesses in PLED structures are much thinner than those of conventional printed films. Thus we will discuss the parameters affecting the film uniformity of the coated layers.

\subsubsection{Gravure printing}

Among conventional roll-toroll printing processes, gravure printing is widely used in printing applications such as newspapers, magazines, and postcards. Gravure printing uses an engraved roll to produce an image pattern similar to in flexography. The printed image by the gravure printing process can be printed by using small dots to produce a whole image. This roll-to-roll printing technique can create a continuous wet film if low-viscosity inks are used. Thus, scalable PLEDs can be fabricated by using the gravure printing process. However, printing instabilities exist, (i.e., irregular streaks), which are frequently reported in the literature. ${ }^{[52,53]}$ High-viscosity inks (PEDOT:PSS and an emissive polymer solution) create extensional viscous flows during gravure printing, as shown in Figure 11. These irregular patterns cause serious problems such as electrical breakage upon driving the device. Thus, it is very important to achieve a uniform coated film without defects and coating instabilities, as shown in Figure 12.

\subsubsection{Screen printing}

Screen printing is a well-known printing technique that uses a woven mesh, and the inks are spread by a squeegee and attached through open areas in the mesh. Finally, the inks are transferred onto target substrates. The thickness is mainly controlled by the viscosity of the inks. To achieve precise image patterns, it requires relatively large viscosity such as that in paste inks. Nevertheless, if a less viscous solution is used to print PLEDs, a continuous film can be produced because the ink transferred from the mesh can be merged into a continuous film. Using a stainless-steel mesh having $40 \mu \mathrm{m}$ sized open areas, a phosphorescence active layer [poly(9-vinylcarbazole) (PVK), 5(4-biphenyl)-2-(4-/m-buty-phenyl)1,3,4-oxadiazole (PBD), N,N'-Di(1-naphthyl)-N,N'-diphenyl(1,1'-biphenyl)-4,4'-diamine (NPD), tris[2-phenylpyridinato- 

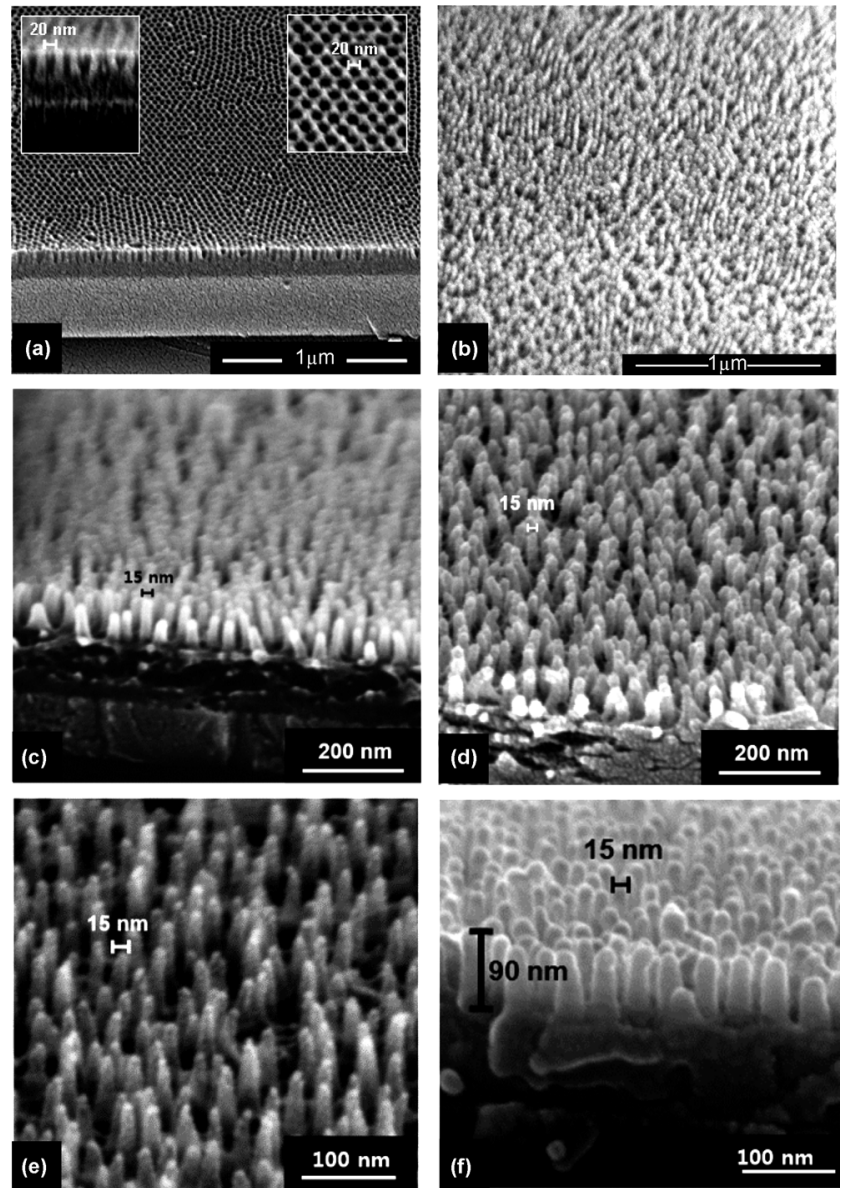

Figure 7. (a) Nanohole-type PDMS soft stamp. Reproduced with permission. ${ }^{[4]]}$ Copyright 2009, American Chemical Society. (b-d) High-aspect-ratio $15 \mathrm{~nm}$ scale polymer semiconductor nanopillars: (b) P3HT, (c) PCDTBT, PIDT PhanQ. (e,f) high aspect ratio $15 \mathrm{~nm}$ scale small molecular organic semiconductor nanopillars: (e) 1-NPSQ, (f) fullerene derivative.

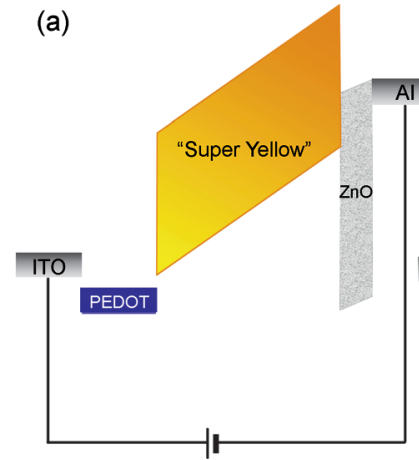

(b)

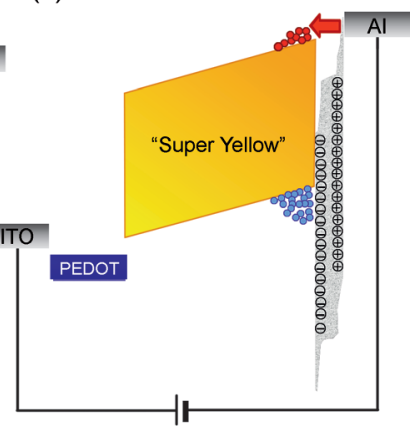

Figure 8. (a) Illustration of ITO/PEDOT/SY/the ZnO NP and ionic interlayer/ Al device under an applied bias. (b) The formation of an interface dipole and the schematic response of the electrons and holes to the interface dipole. Reproduced with permission. ${ }^{[49]}$ Copyright 2010, American Institute of Physics.

C2,N]iridium(III) $\left(\operatorname{Ir}(\mathrm{ppy})_{3}\right)$ ] was fabricated by screen printing, as shown in Figure 13. The device exhibited $12.2 \mathrm{Lm} \mathrm{W}^{-1}$ of power efficiency at a luminance of $470 \mathrm{~cd} \mathrm{~m}^{-2}(15.9 \mathrm{~V})$.

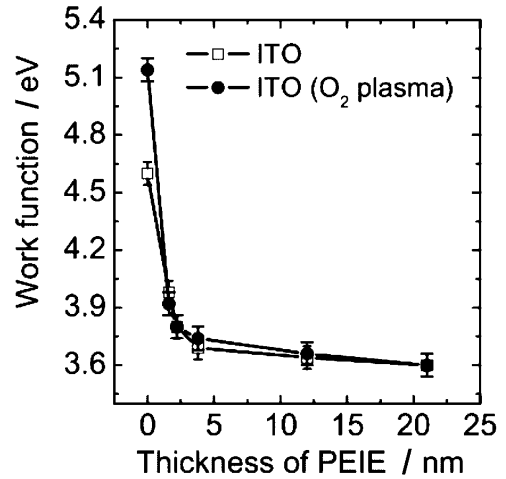

Figure 9. PEIE thickness dependence of the work function of PEIE-coated ITO substrates with $(\bullet)$ and without $(\square) \mathrm{O}_{2}$ plasma treatment. Reproduced with permission. ${ }^{[50]}$ Copyright 2012, Science.
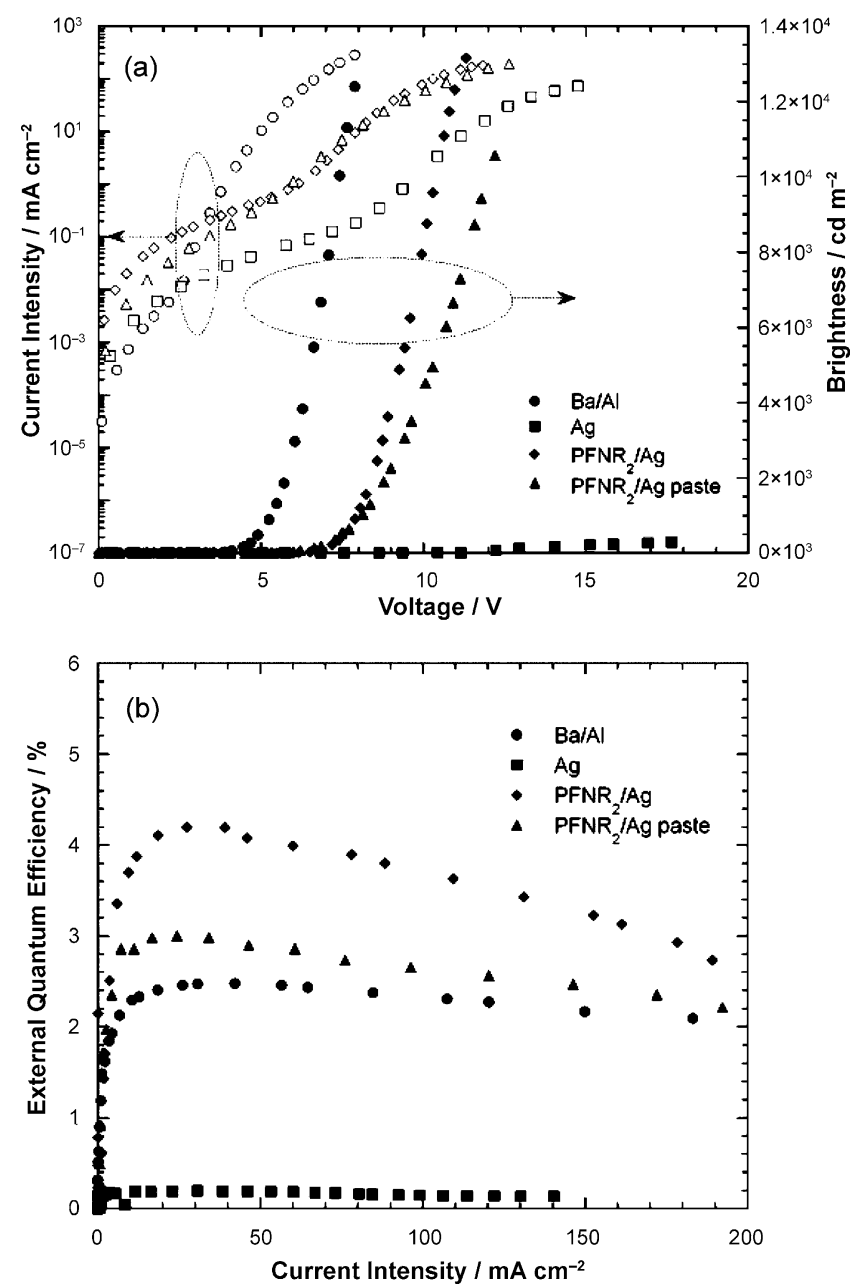

Figure 10. (a) $J-V$ and $L-V$ plots and (b) $Q E-J$ characteristics of P-PPV devices with $\mathrm{Ba} / \mathrm{Al}, \mathrm{Ag}, \mathrm{PFNR}_{2} / \mathrm{Ag}$, and $\mathrm{PFNR}_{2} / \mathrm{Ag}$-paste cathodes. Reproduced with permission. ${ }^{[51]}$ Copyright 2007, Wiley.

\subsubsection{Blade coating}

Blade-coating (or knife-edge coating) is widely used not only in lab-scale but also industrial-scale applications. It is also commonly referred to as doctor blading. In addition, the blade-coating method is compatible with conventional roll- 

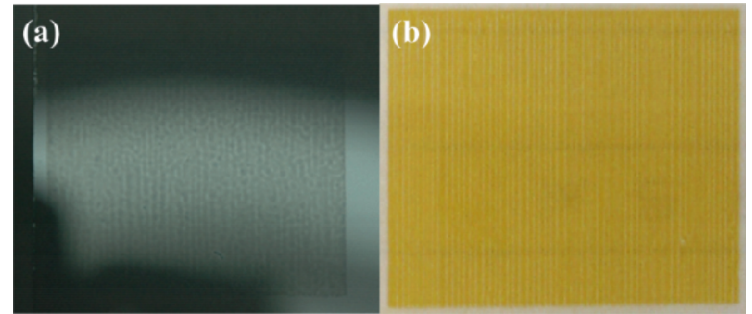

Figure 11. Irregular streak patterns produced by a gravure printing system $\left(15 \mathrm{~kg}_{f}\right.$ printing pressure and printing speed of $\left.20 \mathrm{~m} \mathrm{~min}^{-1}\right)$ : (a) Gravureprinted PEDOT:PSS on PET substrate and (b) Gravure-printed emissive polymer (PDY132: known as super yellow) layer on a PET substrate.

to-roll printing systems. This method was frequently employed to fabricate PLEDs because the blade-coating system is very simple, and the processing is relatively easy. ${ }^{[56,57]}$ However, in terms of film uniformity, the initial thickness of the coated wet film is larger than the final one during the blade coating process. To address this coating non-uniformity, airblowing was employed to achieve a uniform film thickness over the entire coated film surface, as shown in Figure 14. In

(a)

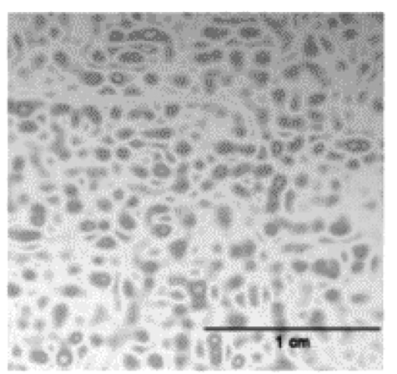

(c)

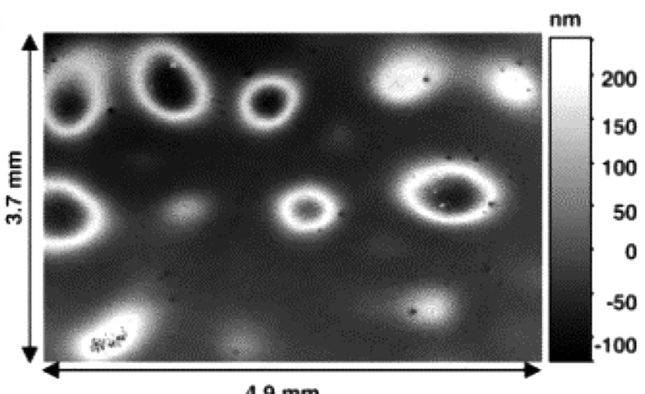

(e)

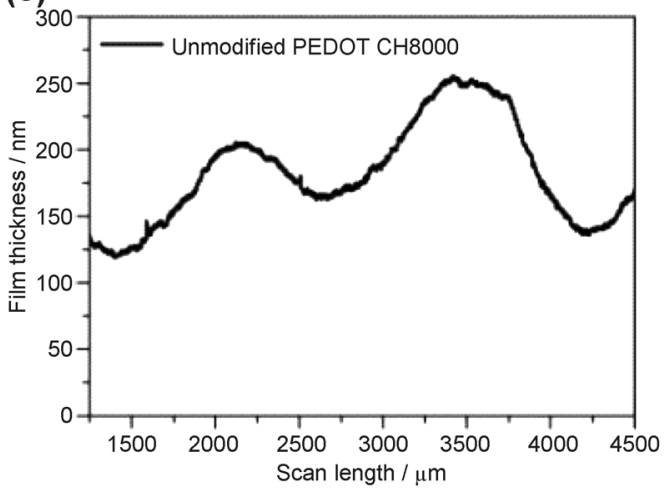

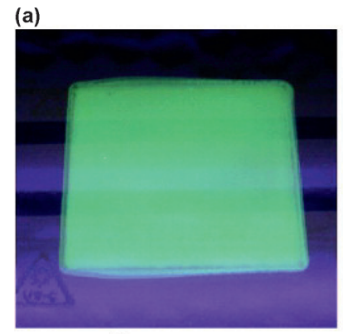
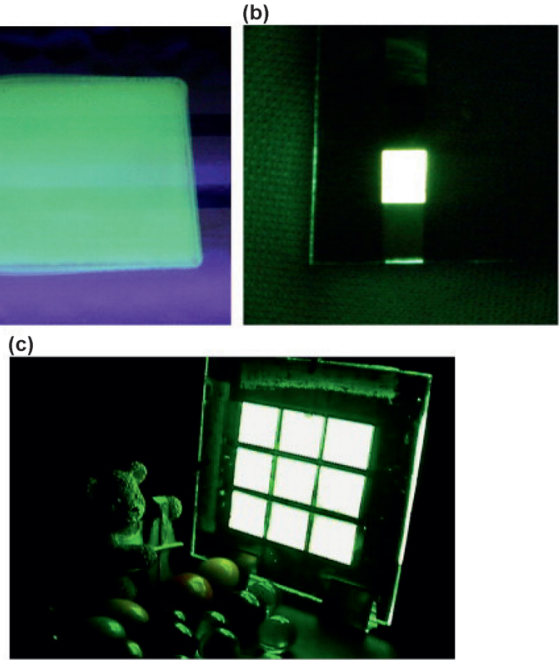

Figure 13. Photographs showing a) The screen-printed area on the patterned ITO substrate, b) EL emission from a small pixel, and c) EL emission from a larger device. Reproduced with permission. ${ }^{[55]}$ Copyright 2008, Elsevier.

(b)

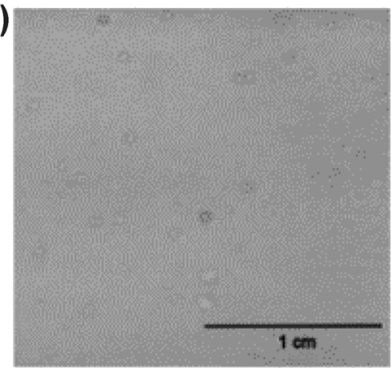

(d)

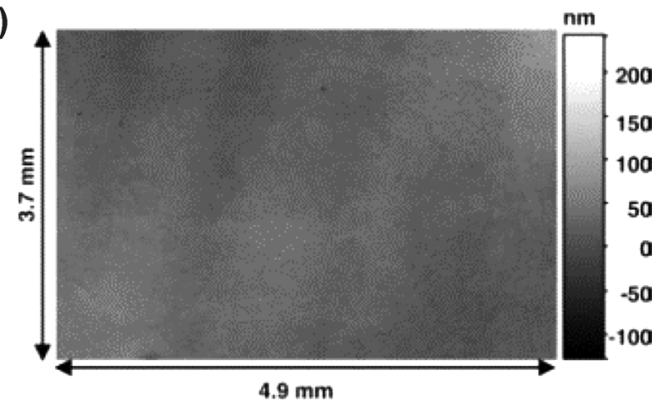

(f)

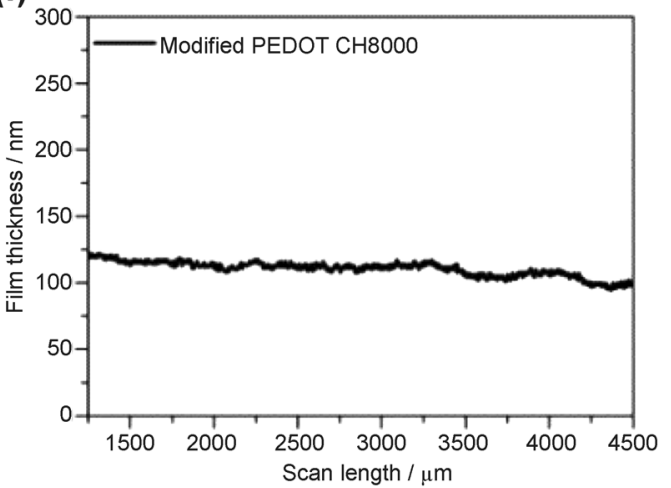

Figure 12. Photographs, 2D surface profiles $\left(4.9 \times 3.7 \mathrm{~mm}^{2}\right)$, and line scans of unmodified $(\mathrm{a}, \mathrm{c}, \mathrm{e})$ and modified (b, d, $\left.\mathrm{f}\right)$ PEDOT. Reproduced with permission. ${ }^{[54]}$ Copyright 2009, Elsevier. 


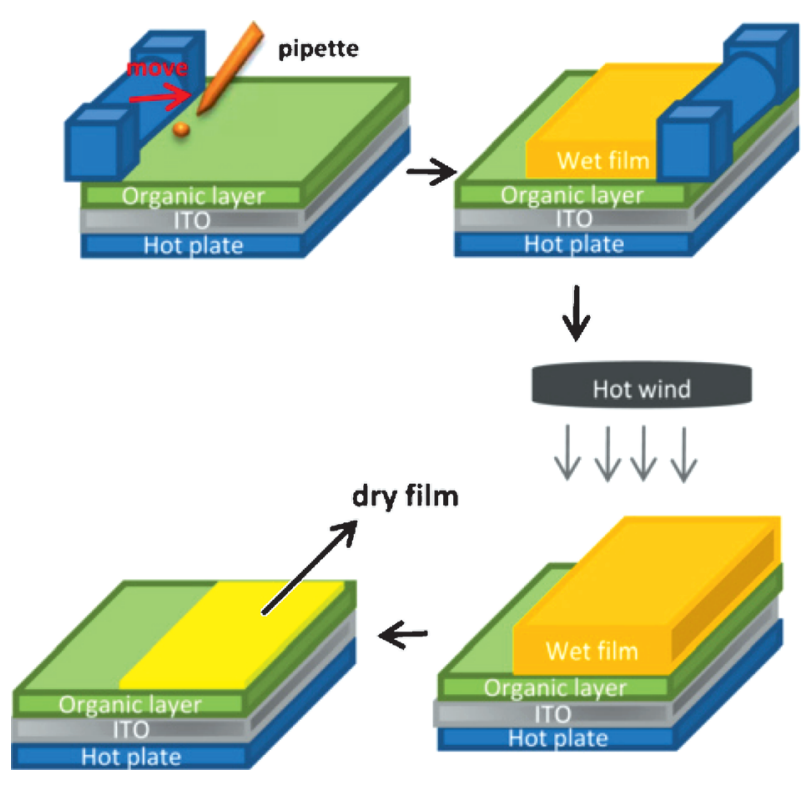

Figure 14. The procedure of the blade-only method. The volume of the solution is controlled precisely by using a macro-pipette. The thickness of the wet film is determined by the gap of the blade coater. The hot air is delivered from a hair dryer with wind mask. Reproduced with permission. ${ }^{[58]}$ Copyright 2014, Springer.

addition, if the blade has a mounted pre-metering unit, the coating uniformity can be much improved as shown in Figure 15. It was found that the non-uniformities of bladeslit-coated PEDOT:PSS and polymer semiconductor layers were $3.8 \%$ and $4.1 \%$, respectively, which represents an improvement over that obtained by using blade-only coating ( $7.9 \%$ and $9.1 \%$, respectively).

\subsubsection{Slot-die coating}

Slot-die coating techniques are used to deposit a wide range of solutions onto a substrate for production in a wide variety of coating/printing applications. This slot-die coating system can precisely supply ink from the reservoir, which creates continuous and uniform wet films by controlling of mass flow rate of the ink and coating speed. Considering that some organic waste solvents are toxic or harmful to the environment, slot-die coating can be an environmentally friendly process because it minimizes this solution waste. Due to these advantages in wet coating, slot-die coating is regarded as a promising process for organic electronics such as OLEDs and OPV cells. As slot-die functionality can be added onto a roll-toroll coating system, it is also useful to deposit solutions onto flexible plastic films such as polyethylene terephthalate (PET) and polyethylene naphthalate (PEN). To fabricate light-emitting electrochemical cells (LECs) by using the slotdie system, thick $(>1 \mu \mathrm{m})$ polymer emissive materials [super yellow, $\mathrm{PEO}$, and potassium triflate $\left.\left(\mathrm{KCF}_{3} \mathrm{SO}_{3}\right)\right]$ were coated onto a substrate, as shown in Figure 16. The best current efficiency achieved was $0.6 \mathrm{~cd} \mathrm{~A}^{-1}$ at a brightness of $50 \mathrm{~cd} \mathrm{~m}^{-2}$.

Similar to the slot-die coating, Youn et al. reported a rollto-roll cohesive coating method that enables the coating of
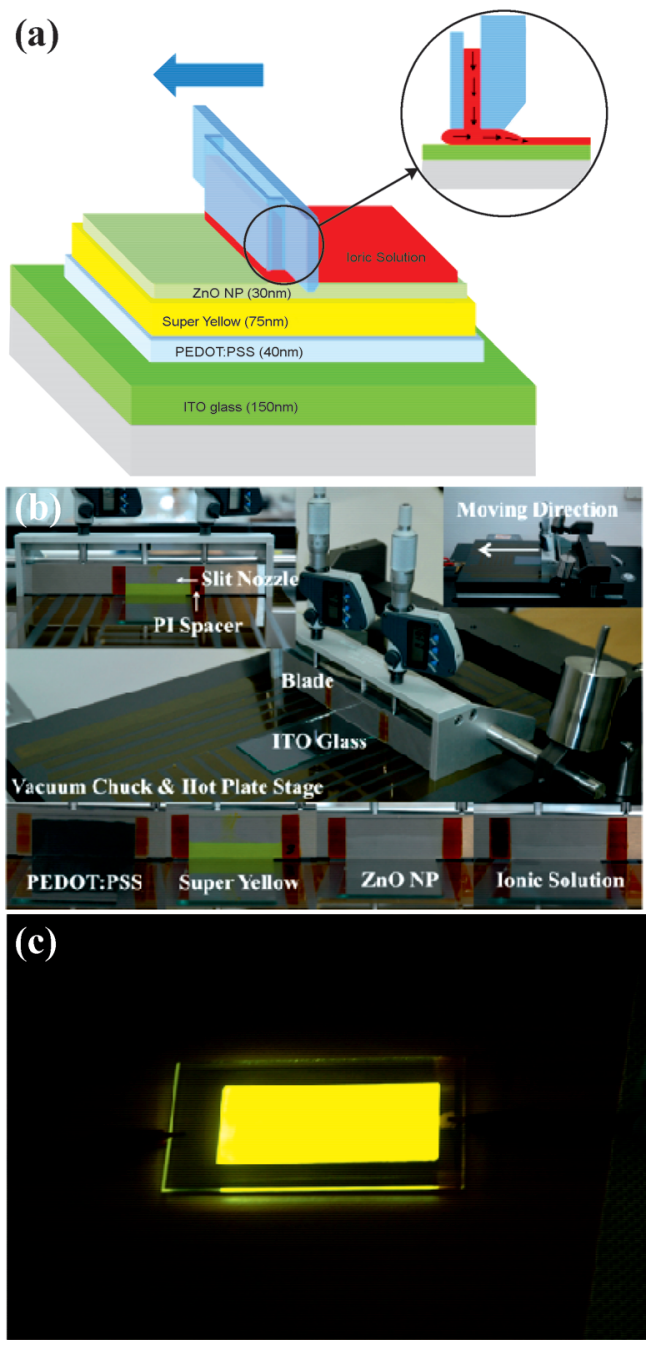

Figure 15. (a) Illustration of the multilayer structure and the fluid flow along the blade, slide glass, and substrate during the fabrication by the blade-slit coating method. (b) The image of the whole systems of the blade-slit coater, the image of the blade-slit nozzle (in left and top of the image), and the images of the blade-slit nozzles containing various solutions for the PLEDs layers (in the bottom of the image). (c) The yellow light-emitting PLEDs on the ITO glass: substrate size $=100 \mathrm{~mm} \times 50 \mathrm{~mm}$. Reproduced with permission. ${ }^{[59]}$ Copyright 2012, Elsevier.

even thinner films because the cohesive coating method only utilizes the cohesive force of the solution (the amount of the solution that can be efficiently minimized from the nozzle) as shown in Figure 17. The PEDOT:PSS, polymer active layer (super yellow), $\mathrm{ZnO}$ layer, and ionic interfacial layer were fabricated by roll coating. The maximum luminous efficiency and power efficiency of the device were approximately $6.1 \mathrm{~cd} \mathrm{~A}^{-1}$ and $5.1 \mathrm{Lm} \mathrm{W}^{-1}$, respectively.

\section{Conclusions}

To fully utilize the unique advantages of flexible organic electronic devices in the field of PV cells and LEDs, advances in printing-based technologies are indispensable. We discussed the progresses in nanoimprint lithography (NIL)based technologies, which are effective in producing interdi- 
(a)
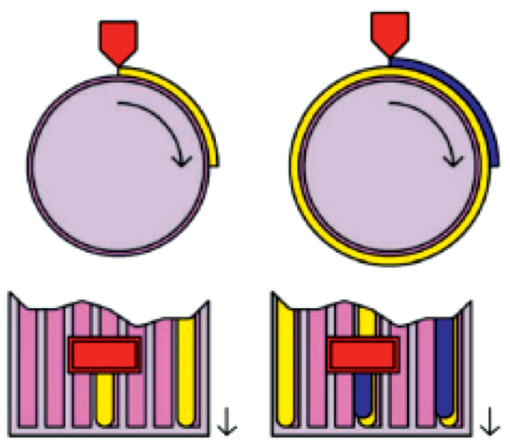

(b)

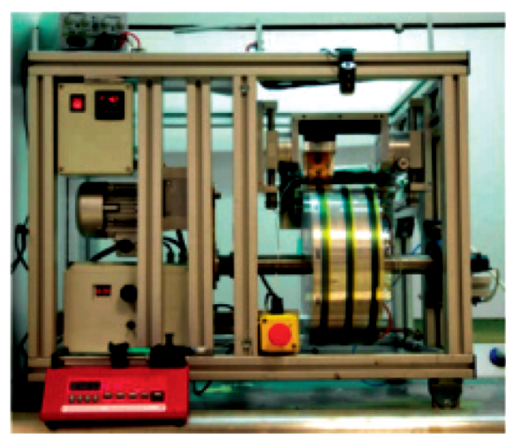

(c)

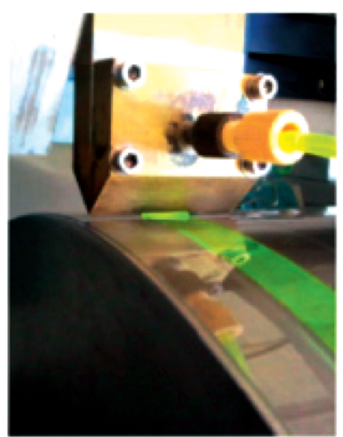

(d)

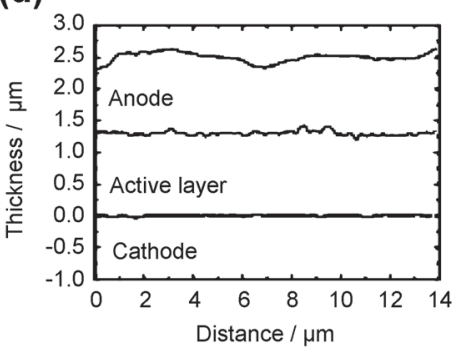

(e)

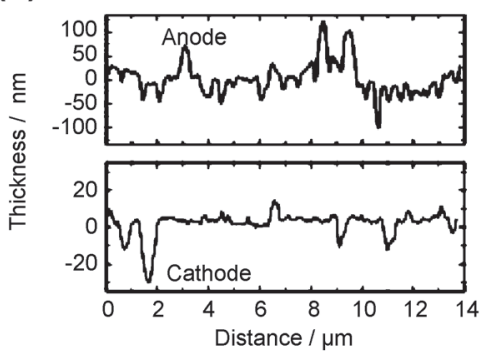

(f)

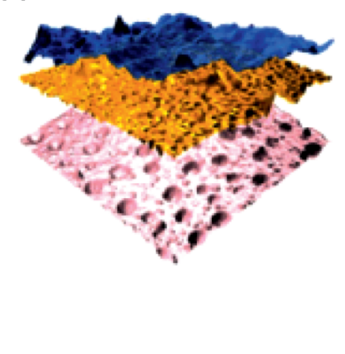

(g)

(h)

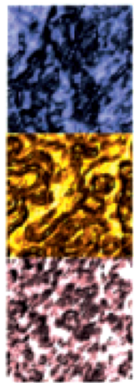

Figure 16. Coating process and morphology and thickness of the coated films. (a) Schematic view of the slot-die roll coating of the (yellow) active layer and the (blue) semitransparent anode on top of a (pink) flexible cathode-coated substrate. The ink is transferred from an external container through a pump to the slot-die head (orange). (b) Photograph of the roll coater during the deposition of the active layer. (c) Close-up photograph of the slot-die head during coating of an active layer stripe. (d) Atomic force microscopy (AFM) data indicating the thickness of the anodic, active, and cathodic layers in the LEC device stack. (e) Enlarged AFM plot indicating the roughness of the anodic and the cathodic interfaces. ( $f$ ) Exploded view of the $10 \times 10 \mu \mathrm{m}^{2}$ AFM height maps of the three constituent layers. (g-i) $2 \times 2 \mu \mathrm{m}^{2}$ AFM phase-contrast images of (g) the PEDOT-PSS anode, ( $h$ ) the active layer, and (i) the $\mathrm{ZnO}$ cathode. Reproduced with permission. ${ }^{[60]}$ Copyright 2012, Nature Publishing Group.

gitated nanostructures of tens of nanometers scale to the photoactive layer to create high-efficiency OPV cells. Various solution-based printing processes such as gravure printing, screen printing, blade coating, and slot-die coating shown great potential as high-throughput manufacturing technologies of PLEDs. These printing-based approaches can help us further advance the technologies of organic electronics.

Figure 17. Illustrations of the cohesive coating mechanism and coating flow details. (a) Adhesive ( $F \mathrm{a})$ and cohesive $(F \mathrm{c})$ force diagram between the hydrophobic and hydrophilic surfaces. Contact angles depend on the relative forces between the solvent molecules and surfaces. In the case of downward concavity, a cohesive force is higher than the adhesive force, whereas upward concavity represents that an adhesive force is higher than the cohesive force. (b) The case of adhesive-force-dominant conditions. Adhesive forces are enhanced by surface energy modification such as $\mathrm{O}_{2}$-plasma treatment. Therefore, the flow rate is reduced by adhesive forces. (c) The case of cohesiveforce-dominant conditions. Adhesive forces are relatively reduced by self-assembled monolayers (SAMs). Thus, the flow rate is increased. Reproduced with permission. ${ }^{[61]}$ Copyright 2013, Wiley.

Molecule (partially $\delta$ - or $\delta$-)

$\longrightarrow$ Cohesive force between liquid and liquid $\left(F_{\mathrm{c}}\right)$ $\leadsto$ Adhesive force between liquid and surface $\left(F_{\mathrm{a}}\right)$ Surface modification

(Self-Assembled Monolayers, $\mathrm{O}_{2}$ Plasma, Teflon film)

- Low-surface-energy region (Downward concavity) - High-surface-energy region (Up ward concavity)
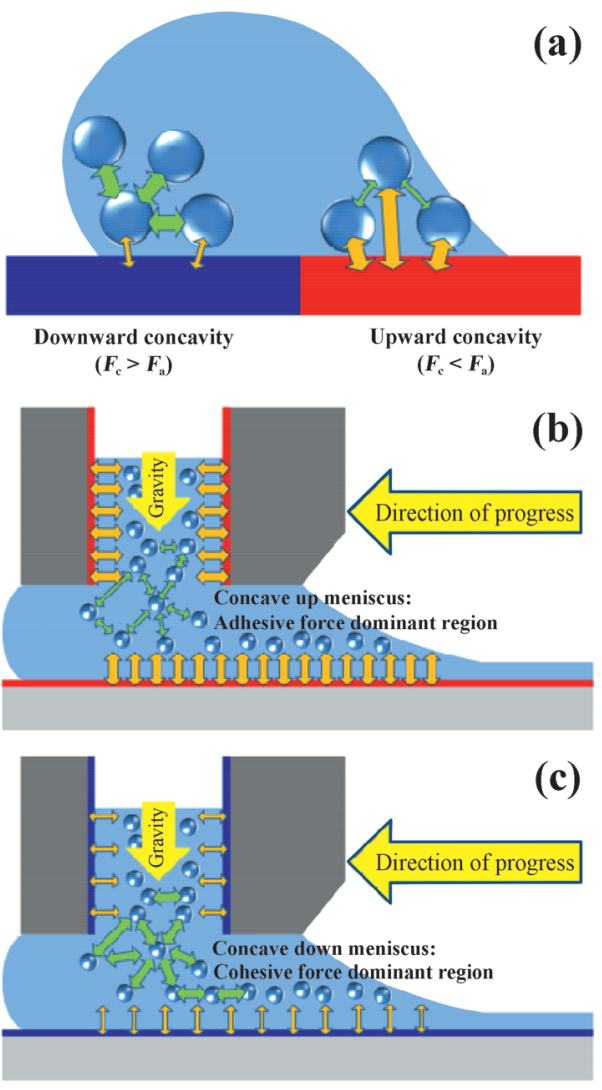


\section{Acknowledgements}

The authors acknowledge partial support by the AFOSR through a subcontract from Omega Optics, NSF, and ONR. HJP acknowledges the support by the Basic Science Research Program through the National Research Foundation of Korea (NRF) funded by the Ministry of Education (2014R1A1A2056403).

Keywords: nanoimprint lithography • organic photovoltaics • polymer light-emitting diodes $\cdot$ print processing $\cdot$ solution processing

[1] Z. He, C. Zhong, X. Huang, W.-Y. Wong, H. Wu, L. Chen, S. Su, Y Cao, Adv. Mater. 2011, 23, 4636.

[2] H.-Y. Chen, J. Hou, S. Zhang, Y. Liang, G. Yang, Y. Yang, L. Yu, Y. Wu, G. Li, Nat. Photonics 2009, 3, 649.

[3] C. E. Small, S. Chen, J. Subbiah, C. M. Amb, S.-W. Tsang, T.-H. Lai, J. R. Reynolds, F. So, Nat. Photonics 2012, 6, 115.

[4] Z. C. He, C. M. Zhong, S. J. Su, M. Xu, H. B. Wu, Y. Cao, Nat. Photonics 2012, 6, 591.

[5] J. M. Halls, K. Pichler, R. H. Friend, S. C. Moratti, A. B. Holmes, Appl. Phys. Lett. 1996, 68, 3120.

[6] L. A. A. Pettersson, L. S. Roman, O. Inganas, J. Appl. Phys. 1999, 86, 487.

[7] M. Theander, A. Yartsev, D. Zigmantas, V. Sundström, W. Mammo, M. R. Anderson, O. Inganas, Phys. Rev. B 2000, 61, 12957.

[8] T. J. Savenije, J. M. Warman, A. Goossens, Chem. Phys. Lett. 1998, $287,148$.

[9] A. Haugeneder, M. Neges, C. Kallinger, W. Spirkl, U. Lemmer, J. Feldman, U. Scherf, E. Harth, A. Gugel, Phys. Rev. B 1999, 59 , 15346.

[10] P. E. Shaw, A. Ruseckas, I. D. W. Samuel, Adv. Mater. 2008, 20, 3516

[11] H. J. Park, J. Y. Lee, T. Lee, L. J. Guo, Adv. Energy Mater. 2013, 3, 1135.

[12] H. Najafov, B. Lee, Q. Zhou, L. C. Feldman, V. Podzorov, Nat. Mater 2010, 9, 938 .

[13] W. A. Luhman, R. J. Holmes, Adv. Funct. Mater. 2011, 21, 764.

[14] G. Yu, J. Gao, J. C. Hummelen, F. Wudl, A. J. Heeger, Science 1995, 270, 1789.

[15] M.-G. Kang, H. J. Park, S. H. Ahn, L. J. Guo, Solar Energy Mater. Solar Cells 2010, 94, 1179.

[16] J. J. M. Halls, C. A. Walsh, N. C. Greenham, E. A. Marseglia, R. H. Friend, S. C. Moratti, A. B. Holmes, Nature 1995, 376, 498.

[17] M. Hiramoto, H. Fujiwara, M. Yokoyama, J. Appl. Phys. 1992, 72, 3781.

[18] H. J. Park, M.-G. Kang, S. H. Ahn, L. J. Guo, Adv. Mater. 2010, 22, E247.

[19] M.-G. Kang, H. J. Park, S. H. Ahn, T. Xu, L. J. Guo, IEEE J. Sel. Top. Quantum Electron. 2010, 16, 1807.

[20] H. J. Park, H. Kim, J. Y. Lee, T. Lee, L. J. Guo, Energy Environ. Sci. 2013, 6, 2203.

[21] B.-G. Kim, E. J. Jeong, H. J. Park, D. Bilby, L. J. Guo, J. Kim, ACS Appl. Mater. Interfaces 2011, 3, 674.

[22] J. Y. Lee, T. Lee, H. J. Park, L. J. Guo, Org. Electron. 2014, 15, 2710.

[23] F.-C. Chen, M.-K. Chuang, S.-C. Chien, J.-H. Fang, C.-W. Chu, J. Mater. Chem. 2011, 21, 11378.

[24] F.-C. Chen, S.-C. Chien, J. Mater. Chem. 2009, 19, 6865.

[25] P. K. Watkins, A. B. Walker, G. L. B. Verschoor, Nano Lett. 2005, 5, 1814.

[26] F. Yang, S. R. Forrest, ACS Nano 2008, 2, 1022.

[27] L. J. Guo, Adv. Mater. 2007, 19, 495.

[28] Y. Matsuo, Y. Sato, T. Niinomi, I. Soga, H. Tanaka, E. Nakamura, J. Am. Chem. Soc. 2009, 131, 16048
[29] M. Hirade, H. Nakanotani, M. Yahiro, C. Adachi, ACS Appl. Mater. Interfaces 2011, 3, 80.

[30] F. Yang, M. Shtein, S. R. Forrest, Nat. Mater. 2005, 4, 37.

[31] N. Li, S. R. Forrest, Appl. Phys. Lett. 2009, 95, 123309.

[32] S. Yu, C. Klimm, P. Schafer, J. P. Rabe, B. Rech, N. Koch, Org. Electron. 2011, 12, 2180.

[33] M.-S. Kim, J.-S. Kim, J. C. Cho, M. Shtein, L. J. Guo, J. Kim, Appl. Phys. Lett. 2007, 90, 123113.

[34] M. Aryal, F. Buyukserin, K. Mielczarek, X.-M. Zhao, J. Gao, A. Zakhidov, W. Hu, J. Vac. Sci. Technol. B 2008, 26, 2562.

[35] D. Chen, W. Zhao, T. P. Russell, ACS Nano 2012, 6, 1479.

[36] E. Avnon, N. Yaacobi-Gross, E. Ploshnik, R. Shenhar, N. Tessler, Org. Electron. 2011, 12, 1241.

[37] Y. Yang, M. Aryal, K. Mielczarek, W. Hu, A. Zakhidov, J. Vac. Sci. Technol. B 2010, 28, C6M104.

[38] J. S. Kim, Y. Park, D. Y. Lee, J. H. Lee, J. H. Park, J. K. Kim, K. Cho, Adv. Funct. Mater. 2010, 20, 540.

[39] X. He, F. Gao, G. Tu, D. Hasko, S. Hüttner, U. Steiner, N. C. Greenham, R. H. Friend, W. T. S. Huck, Nano Lett. 2010, 10, 1302.

[40] X. He, F. Gao, G. Tu, D. G. Hasko, S. Hüttner, N. C. Greenham, U. Steiner, R. H. Friend, W. T. S. Huck, Adv. Funct. Mater. 2011, 21, 139.

[41] H. J. Park, M.-G. Kang, L. J. Guo, ACS Nano 2009, 3, 2601.

[42] L. S. Hung, C. W. Tang, M. G. Mason, Appl. Phys. Lett. 1997, 70, 152.

[43] C. Wu, G. Lee, T. Pi, Appl. Phys. Lett. 2005, 87, 212108.

[44] P. Piromreun, H. S. Oh, Y. Shen, G. G. Malliaras, J. C. Scott, P. J. Brock, Appl. Phys. Lett. 2000, 77, 2403.

[45] G. Li, J. Shinar, Appl. Phys. Lett. 2003, 83, 5359.

[46] J. Lee, Y. Parka, D. Y. Kim, H. Y. Chu, H. Lee, L. M. Do, Appl. Phys. Lett. 2003, 82, 173.

[47] J. Huang, Z. Xu, Y. Yang, Adv. Funct. Mater. 2007, 17, 1966.

[48] H. Siemund, F. Bröcker, H. Göbel, Org. Electron. 2013, 14, 335.

[49] H. Youn, M. Yang, Appl. Phys. Lett. 2010, 97, 243302.

[50] Y. Zhou, C. Fuentes-Hernandez, J. Shim, J. Meyer, A. J. Giordano, H. Li, P. Winget, T. Papadopoulos, H. Cheun, J. Kim, M. Fenoll, A. Dindar, W. Haske, E. Najafabadi, T. M. Khan, H. Sojoudi, S. Barlow, S. Graham, J.-L. Brédas, S. R. Marder, A. Kahn, B. Kippelen, Science 2012, 336, 327.

[51] W.J. Zeng, H.B. Wu, C. Zhang, F. Huang, J.B. Peng, W. Yang, Y. Cao, Adv. Mater. 2007, 19, 810.

[52] D.-Y. Chung, J. Huang, D. D. C. Bradley, A. J. Campbell, Org. Electron. 2010, 11, 1088.

[53] J. J. Michels, S. H. P. M. Winter, L. H. G. Symonds, Org. Electron. 2009, 10, 1495 .

[54] P. Kopola, M. Tuomikoski, R. Suhonen, A. Maaninen, Thin Solid Films 2009, 517, 5757.

[55] D.-H. Lee, J. S. Choi, H. Chae, C.-H. Chung, S. M. Cho, Displays 2008, 29, 436.

[56] S.-R. Tseng, H.-F. Meng, K.-C. Lee, S.-F. Horng, Appl. Phys. Lett. 2008, 93, 153308 .

[57] C.-Y. Chen, H.-W. Chang, Y.-F. Chang, B.-J. Chang, Y.-S. Lin, P.-S. Jian, H.-C. Yeh, H.-T. Chien, E.-C. Chen, Y.-C. Chao, H.-F. Meng, H.-W. Zan, H.-W. Lin, S.-F. Horng, Y.-J. Cheng, F.-W. Yen, I.-F. Lin, H.-Y. Yang, K.-J. Huang, M.-R. Tseng, J. Appl. Phys. 2011, 110, 094501.

[58] "Low-Cost Fabrication of Organic Photovoltaics and Polymer LEDs": H.-S. Youn, H.-S. Kim, L. J. Guo in Low-cost Nanomaterials: Toward Greener and More Efficient Energy Applications (Eds.: Z. Q. Lin, J. Wang), Springer, London, 2014, pp. 227-266.

[59] H. Youn, K. Jeon, S. Shin, M. Yang, Org. Electron. 2012, 13, 1470

[60] A. Sandström, H. F. Dam, F. C. Krebs, L. Edman, Nat. Commun. 2012, 3, 1002.

[61] S. Shin, M. Yang, L. J. Guo, H. Youn, Small 2013, 9, 4036.

Received: October 29, 2014

Revised: December 26, 2014

Published online on February 27, 2015 